\title{
Estudantes de enfermagem têm perfil empreendedor?
}

\author{
Do nursing students have entrepreuner profile? \\ ¿Estudiantes de enfermería tienen perfil emprendedor?
}

\author{
Paulo Fernando Roncon', Sarah Munhoz' \\ 'Universidade de Santo Amaro. Curso de Enfermagem. São Paulo, SP
}

Submissão: 12/12/2008

Aprovação: 10/08/2009

\section{RESUMO}

Estudo descritivo-exploratório Que teve como objetivo conhecer o perfil dos estudantes concluintes de um curso de graduação em enfermagem Quanto ao empreendedorismo. O Teste de Tendência Empreendedora Geral, contendo 54 Questões, foi aplicado a 41 estudantes. Os resultados demonstraram Que I $4 \%$ apresentam cinco tendências empreendedoras e 12\% Quatro tendências empreendedoras; $80 \%$ apresentam fraca ou nenhuma tendência empreendedora. A grande maioria pretende encaminhar sua a profissão em atividades assistenciais, eneuanto nenhum dos estudantes pretende atuar em atividades administrativas. Conclui-se Que, os estudantes possuem baixo grau de presença de características empreendedoras.

Descritores: Emprego; Mobilidade ocupacional; Ocupações; Estudantes de enfermagem; Enfermagem.

\section{ABSTRACT}

Descriptive-exploratory study that aimed at knowing the profile of nursing students regarding entrepreneurship. The General Entrepreneurship Trend Test with 54 Questions was applied to 41 students. Results demonstrated that $14 \%$ present five entrepreneur tendencies, $12 \%$ present four entrepreneur tendencies, and $80 \%$ do not present entrepreneur tendencies. The majority of student intent to work as clinical nurses, while none of them intent to work in management activities. It was concluded that students have low grade of the entrepreneurship characteristics.

Descriptors: Employment; Career mobility; Occupations; Nursing students; Nursing.

\section{RESUMEN}

Estudio descriptivo-exploratorio Que tvo como objetivo conocer el perfil de los estudiantes concluintes de un curso de grado de enfermería cuanto al espíritu emprendedor. El Test General de Tendencia Emprendedora contiendo 54 cuestiones fue aplicado a 41 estudiantes. Resultados demostraran que I $4 \%$ tienen cinco tendencias de emprendedor, 12\% tienen cuatro tendencias de emprendedor, 80\% no tienen tendencias de emprendedor. La mayoría desea trabajar con actividades asistenciales, mientras ninguno de ellos desean trabajar con actividades administrativas. Se concluye Que los estudiantes tienen bajo grado de presencia de características emprendedoras. Descriptores: Empleo; Movilidad laboral; Ocupaciones; Estudiantes de enfermería; Enfermería. 


\section{INTRODUÇÃO}

O emprego-padrão de hoje, com vínculo salarial, patrão e horário rígido, já é um artefato pertencente ao passado. Neste novo século as vagas de emprego nos hospitais e serviços de saúde estarão cada vez mais enxutas, devido às crises financeiras do setor e à falta de conhecimento atualizado dos profissionais. Com tão poucas oportunidades, o emprego assalariado na área de saúde em curto espaço de tempo estará caminhando para a extinção no Brasil a exemplo de países da América do Norte e Europa.

O novo milênio chegou e com ele a "Era do Conhecimento", como muitos chamam, proporciona acesso a um número de informações muito maior do Que podemos absorver, e, ao mesmo tempo, nunca se teve tanta incerteza sobre o futuro profissional. $\mathrm{O}$ Que fazer? Quais as alternativas?

Para muitos profissionais que estudam a tendência do mercado de trabalho a resposta é muito simples: Seja "presidente" de sua própria vida. É a era do emprego por conta própria ${ }^{(1)}$.

Fugir do convencional; sonhar alto e transformar sonhos em realidade; identificar com clareza desejos, habilidades, temperamentos e atividades; criar um produto; desenvolver um plano de negócios da própria carreira; fazer o Que se gosta; investir no desenvolvimento contínuo; conciliar a vida profissional com a vida pessoal e familiar; cuidar da saúde física, mental e emocional; seguir a intuição são passos para sobreviver no mundo moderno ${ }^{(2)}$.

Principalmente na área de saúde não estão faltando oportunidades. O Que falta é uma melhor condução da carreira entendo-a como um negócio e não como sacerdócio. Aos poucos a postura profissional do enfermeiro tem mudado, mas agora o mundo requer destes profissionais um grande salto.

Urge a necessidade de se redesenhar a carreira, mudar de carreira, mudar de empresa ou até mesmo abrir um negócio próprio, tornando-se um empreendedor. Mesmo optando por continuar na folha de pagamento da empresa como assalariado, pode-se agir e pensar como um intra-empreendedor ${ }^{(3)}$. O Que vem a ser um "empreendedor"?

O empreendedor é alguém Que define metas, busca informações e é obstinado. Embora muitas pessoas adQuiram estas características sem precisar freqüentar cursos, tem-se a firme convicção de Que elas podem ser desenvolvidas e lapidadas ${ }^{(4)}$.

As funções inovadoras e de promoção de mudanças do empreendedor Que, ao combinar recursos em uma maneira original, servem para promover o desenvolvimento e crescimentos econômicos. A figura do empreendedor na área de saúde é nova e ganha nestes novos tempos de tecnologia avançada e altamente mutável, um destaque em função da necessidade de gerar novos postos de trabalho. O desemprego, no âmbito mundial, alcança hoje os níveis mais altos desde a crise dos anos 30.

No Brasil, esta situação vem se agravando e as instabilidades do mundo atual, veja, por exemplo, a crise dos bancos e conseQüente inQuietação das bolsas de valores, dos negócios em geral ocorridos no dia 01 de outubro de 2008, concorrem para Que aja um crescente número de pessoas subempregadas e desempregadas. Redefinir oportunidades e responsabilidades para milhões de pessoas numa sociedade, sem o emprego de massa formal, deverá ser a Questão social mais premente do próximo século ${ }^{(6)}$. Estas Questões avaliadas serviram para criar um cenário Que indicou Que enfermeiros precisam criar olhos e competências para ser um empreendedor no âmbito pessoal e profissional.

Tanto nas Questões do empreendedorismo como na enfermagem, mais importante do Que saber fazer é criar o Que fazer, reconhecer a cadeia econômica, o ciclo produtivo, entender do negócio, saber transformar necessidades em especificações técnicas, transformando o conhecimento em riqueza. Mas como se preparar para criar um negócio próprio, ou seja, como ser um empreendedor?

Alguns autores apresentam como resposta a este Questionamento os seguintes passos:

- Desenvolver uma íntima relação com os computadores, mesmo parecendo uma Questão óbvia sem este conhecimento, o empreendedor não terá acesso às informações necessárias para seu desenvolvimento profissional e pessoal.

- Dominar os princípios básicos de administração, principalmente no Que tange a administração de micro-empresas, pois existe uma grande probabilidade de Que o negócio inicie com apenas um ou dois funcionários.

- Aprender a trabalhar em equipe, pois as distâncias entre empregador e empregado estão cada vez menores.

- Não se apegar demasiadamente a detalhes, pois o mundo está mudando rapidamente, de modo Que não adianta uma superespecialização em um assunto Que, provavelmente, ao fim dos estudos, estará ultrapassado.

- Fazer aquilo de Que gosta, meditando antes de iniciar um empreendimento se isso é realmente o que você gostaria de fazer pelo resto de sua vida.

- Ser otimista, acreditando em si e na capacidade de vencer.

\section{Tipos de Empreendedorismo}

Ao verificar os tipos de pessoas empreendedoras, encontrou-se na literatura diferentes tipos de empreendedor ${ }^{(6)}$, a saber:

- Empreendedor artesão: o indivíduo Que é essencialmente um técnico e escolhe instalar um negócio independente para praticar o seu ofício.

- Empreendedor tecnológico: o indivíduo associado ao desenvolvimento ou comercialização de um novo produto ou processo inovador e que monta uma empresa para introduzir essas melhorias tecnológicas e obter lucro.

- Empreendedor oportunista: o indivíduo Que enfoca o crescimento e o ato de criar uma nova atividade econômica e Que monta, compra e faz crescer empresas, em resposta a uma oportunidade observada.

- Empreendedor "estilo de vida": o indivíduo autônomo ou que começa um negócio por causa da liberdade, independência e/ou outros benefícios para seu estilo de vida, Que seu empreendimento torna possíveis.

Ser empreendedor significa ter, acima de tudo, a necessidade de realizar coisas novas, pôr em prática idéias próprias, característica de personalidade e comportamento Que nem sempre é fácil de encontrar. O empreendedor, por definição, tem de assumir riscos, e seu sucesso está em sua capacidade de conviver com eles e sobreviver a eles. Os riscos fazem parte de Qualquer atividade e é preciso aprender a administrá-los. O empreendedor não é malsucedido nos seus negócios porque sofre revezes, mas porQue não sabe superá-los.

Neste contexto, o desafio da economia brasileira na era da 
globalização, e principalmente na área de saúde, é conseguir reestruturar toda uma base produtiva criada sob os padrões tecnológicos e de gestão dos países mais desenvolvidos, "pois a gestão social responsável, Quando implementada em toda a cadeia produtiva, aumenta e eficiência do processo produtivo e promove o desenvolvimento da cidadania como um todo. Esse processo resulta na consolidação da parceria conQuistada mediante o relacionamento transparente entre as empresas e a extensão da gestão social aos stakeholder (parte interessada ou interveniente, refere-se a todos os envolvidos num processo, por exemplo, clientes, colaboradores, investidores, fornecedores, comunidade etc. O processo em Questão pode ser de carácter temporário (como um projeto) ou duradouro (como o negócio de uma empresa ou a missão de uma organização sem fins lucrativos) ${ }^{(7)}$.

Atualmente, as economias Que registram as taxas de crescimento mais altas do mundo têm seu "grande motor" na atividade dos empreendedores, cujas empresas geram a maior Quantidade de novos empregos ${ }^{(8,9)}$

Experiências empresariais bem-sucedidas, utilizando novas abordagens na gestão das empresas, por meio da humanização da administração, da integração sistêmica e ambiental, cada vez mais acentuam e mostram a necessidade de relações inovadoras e criativas na gestão de empreendimentos. Tais abordagens são acessíveis a Quaisquer empresas, independentemente de seu porte ou campo de ação ${ }^{(10)}$.

Assim, após a verificação de todo este referencial ficou uma pergunta no Que concerne ao profissional enfermeiro: Será Que ele tem perfil para desenvolver ações empreendedoras? Em virtude deste Questionamento, propôs-se realizar a presente pesquisa verificando se dentre os graduandos de enfermagem são observadas caracteristicas Que possam sugerir o perfil empreendedor nos futuros enfermeiros.

Considerando este contexto este estudo teve como objetivo conhecer o perfil dos graduandos em enfermagem em relação às características empreendedoras.

\section{MÉTODO}

Trata-se de uma pesquisa com desenho não-experimental do tipo descritivo-exploratória Que buscou identificar traços de empreendedorismo em um grupo de graduandos de enfermagem mediante afirmações de situações pré-formuladas.

A peseuisa foi realizada em uma universidade privada localizada na zona sul de São Paulo com alunos do oitavo semestre do curso de graduação em enfermagem.

A composição amostral foi do tipo não-probabilística de conveniência, procurando atingir a totalidade da população em estudo. Participaram do estudo $4 \mathrm{I}$ alunos mediante a anuência e assinatura do TCLE.

O projeto de pesquisa obedeceu as normas da Resolução $n^{\circ}$ 196/96 do Conselho Nacional de Saúde, e foi previamente aprovado pelo comitê de Ética em PesQuisa da instituição com o registro 103/2008.

A coleta de dados foi feita em Setembro de 2008. O formulário escolhido foi o Teste de Tendência Empreendedora Geral (TEG) pelo fato de apresentar Questões de fácil compreensão e de respostas rápidas (dupla escolha), e Que atendia ao reQuisito da identificação de traços empreendedores (desejos, impulsos e atitudes) Que asseguram uma disposição para assumir responsabilidades, determinação para acabarem projetos, a criatividade Que leva à inovação e uma tolerância positiva a riscos moderados ${ }^{(11)}$.

Para identificar se o graduando possui ou não aquela dimensão da TEG, ele deve alcançar um mínimo de pontos. Com base nessas informações foi gerada a variável independente deste estudo, Que é o nível de tendência empreendedora do graduando de enfermagem.

Se o respondente teve apenas uma ou nenhuma das dimensões de tendência empreendedora, o nível foi tido como "muito baixo"; se duas tendências, o nível foi considerado "baixo"; Quando três tendências, foi considerado "médio"; com Quatro, era tido "alto"; e, para aQueles que tivessem as cinco tendências empreendedoras, o nível era considerado "muito alto".

Caird $^{(12)}$ apresenta as definições para Teste de Tendência Empreendedora Geral (TEG) Que separa estas características em cinco dimensões, identificando em Que os empreendedores de maior sucesso têm altas pontuações, em cada uma delas:

a) necessidade de sucesso: Que representa o empreendedor Que possui algumas Qualidades como: visão futura, auto-suficiência, postura mais otimista do Que pessimista, orientação para as tarefas e para os resultados, incansabilidade e energia, confiança em si mesmo, persistência e determinação, além de dedicação para concluir uma tarefa;

b) necessidade de autonomia/independência: representando as Qualidades de realização por intermédio de atividades pouco convencionais, preferência por trabalhar sozinho, necessidade de priorizar os seus objetivos pessoais e expressar o Que pensa, preferência por tomar decisões ao invés de receber ordens, não se rende à pressão do grupo de trabalho;

c) tendência criativa: Que condensa as Qualidades de imaginação e inovação, tendência de sonhar acordado, versatilidade e curiosidade, geração de muitas idéias, intuição, gosto por novos desafios, novidade e mudança;

d) propensão a riscos: refletida por Qualidades como atuação mesmo com informações incompletas, julgamento Quando dados incompletos são suficientes, valorização com precisão de suas próprias capacidades, ambição em um nível adeQuado, avaliação de custos e benefícios correta, fixação de objetivos desafiadores, mas Que podem ser realizados; e

e) impulso e determinação: Que representa a tendência do empreendedor possuir as Qualidades de: aproveitamento de oportunidades, não aceitação de predestinação, atuação no sentido de controlar seu próprio destino, autoconfiança, equilíbrio entre resultado e esforço e considerável determinação.

A análise dos dados foi obtida por estatística descritiva, com dados absolutos e relativos. Devido à limitação da amostra e Que as respostas são inferências é importante ressaltar Que os resultados abaixo apresentados não devem ser generalizados.

\section{RESULTADOS}

\section{Perfil graduandos segundo dados pessoais e profissionais}

Dos 41 formulários preenchidos, conclui-se Que os sujeitos da pesquisa tinham o seguinte perfil: Quanto à idade, $85 \%$ tinham pertenciam a uma faixa etária inferior a 30 anos. Quanto ao gênero, 
observou-se a predominância do sexo feminino (83\%). Nesta Questão específica o predomínio do sexo feminino nessa amostra está de acordo com os dados observados na literatura, confirmandose a "feminilização" da força de trabalho da categoria.

O aluno trabalhador apareceu como grande maioria (56\%), sendo Que destes $60 \%$ são trabalhadores na área da saúde, atuantes na região do entorno da universidade e tendo um emprego. Daqueles Que se disseram trabalhadores, 39\% não declarou o tempo de serviços, e $21 \%$ referiu tempo de serviço em período igual ou inferior a cinco anos e $21 \%$ referiu tempo de serviço entre seis e sete anos.

Quanto à pretensão de prosseguimento dos estudos no nível de especialização, 70\% pretende buscar preparo para desenvolvimento de suas atividades na área hospitalar, 21\% deseja fazer mais de uma especialização, 7\% optou para direcionarem sua formação na área da docência e não foi encontrada menção de pretensão para a área de gestão.

\section{Nível de características empreendedoras dos graduandos de enfermagem}

Para a avaliação do Gráfico I, foi considerado para como requisitos da avaliação os seguintes dados:

- Se o graduando obteve resultados "muito alto" e "alto" em apenas uma ou nenhuma das dimensões de tendência empreendedora, o nível foi tido como "muito baixo";

- Resultados "muito alto" e "alto" em duas tendências o nível foi considerado "baixo";

- Resultados "muito alto" e "alto" em três tendências foi considerado "médio";

- Resultados "muito alto" e "alto" em Quatro tendências "alto"; e

- Resultados "muito alto" e "alto" para aqueles que tivessem as cinco tendências empreendedoras, o nível era considerado "muito alto".

Assim pode-se constatar Que Quando avaliadas somente a pontuação muito alto e alto, em todas as tendências empreendedoras, não foram encontrados resultados positivos Que Qualificassem os graduandos de enfermagem dentro de uma forte tendência para a competência empreendedorismo.

Assim, houve-se por bem Qualificar no nível médio Quantas foram as tendências alcançadas, obtendo os seguintes resultados:

Dos 41 graduandos respondentes, 14\% demonstrou cinco tendências em nível médio, 12\% apresentou Quatro tendências empreendedoras. Para efeito de corte e subsidio da análise considerou-se Que os graduandos Que tiveram pontuação média em três tendências ou menos tinham baixo grau de presença de características da competência empreendedorismo.

Desta feita, constatou-se Que $80 \%$ dos estudantes apresenta fraeuíssima ou nenhuma tendência empreendedora (Gráfico I).

\section{DISCUSSÃO}

Na dimensão necessidade de dimensão esteve presente em 41\% dos casos. Sendo que dois deles apresentaram a pontuação máxima (muito alta), Quatro apresentaram pontuação alta e os demais as pontuações foram muito baixas ou ausentes.

Nesta perspectiva esperava-se uma Quantidade de respostas mais significativas uma vez Que o enfermeiro mesmo na administração

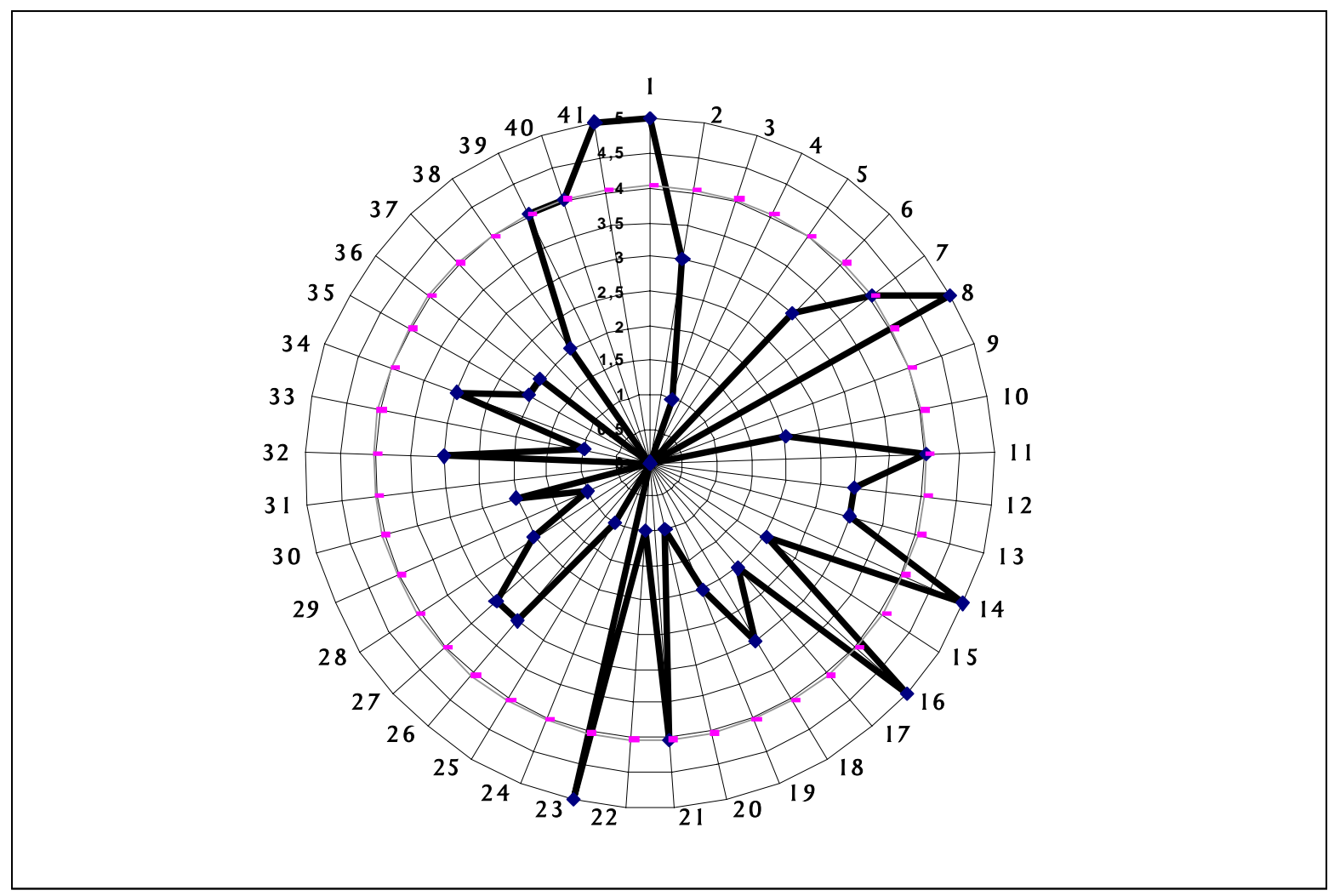

Gráfico 1. Quantidade de tendências empreendedoras no nível médio por Quantidade de dimensões alcançadas. São Paulo, 2008. 
do serviço e da assistência tem Que exercitar e encampar no seu perfil profissional aspectos como a postura de orientação para as tarefas e para os resultados, confiança em si mesmo, persistência e determinação, além de dedicação para concluir uma tarefa, pois a "enfermagem como área do conhecimento e de saber possui um amplo universo Que perpassa as técnicas do fazer e Quando o enfermeiro detém a posse do conhecimento, garante uma posição e credibilidade diferenciada como líder no gerenciamento de enfermagem"(14).

Em trabalhos sobre o perfil do enfermeiro e necessidades de desenvolvimento de competência profissionais, pode-se encontrar como o requisito que "o atendimento de enfermagem ao ser humano deve ser considerado em sua totalidade e em constante interação com o meio ambiente, Que o enfermeiro atua em diversos campos de ação, exercendo atividades de assistência, administração, ensino, pesQuisa e integração, nos níveis primário, secundário e terciário e Que a constante evolução das ciências da saúde exige do enfermeiro permanente atualização e, muitas vezes, especialização, Que deve ser adQuirida após a formação básica"(15).

Por outro lado, a dimensão necessidade de autonomia e independência acima da média foi encontrada em $51 \%$ dos casos. Do ponto de vista das relações sociais, um trabalho é autônomo se e somente se é empreendido sem a intermediação de outras ações conduzidas por outros profissionais para começar ou terminar. A presença de diversos elementos na realidade do trabalho da enfermagem a configuram como uma profissão Que possibilita ao enfermeiro amplos espaços de exercício de autonomia e de poder decisório assim a ausência desta tendência em $49 \%$ dos entrevistados nos leva a crer Que isto pode ser um indicio de Que os graduandos de enfermagem ainda não se permitiram romper com o mito de ser a enfermagem uma profissão subalterna, porQue estão impregnados, dentre outros, de sentimentos de impotência, limitação, desprestígio, desvalorização e falta de reconhecimento ${ }^{(16,17)}$.

De uma forma destacada, a dimensão de tendência criativa, foi a Que menos apareceu neste estudo (36\%). É importante salientar Que a criatividade está relacionada com fatores de sucesso, assim as escolas precisam propor iniciativas Que, muito além de capacitar profissionais de saúde com competência técnica especializada, é necessário o desenvolvimento de pessoas comprometidas com o processo de gestão, Que exige Qualidades como a criatividade, a inovação, a intuição, a emoção entre outras ${ }^{(17)}$.

A dimensão de propensão ao risco mostrou-se presente em $60 \%$ dos casos. Provavelmente a capacidade desenvolvida nos graduandos para agir com informações incompletas em determinadas situações de urgência e enfrentar desafios, geraram este resultado principalmente porQue foram durante os Quatro anos da graduação treinados por profissionais mais experientes para gerarem, mesmo com menos informações, respostas Que podem atender ou mesmo superar as expectativas dos clientes. Normalmente, o enfermeiro dentro de sua formação é treinado para captar, entender e atender as necessidades do cliente dandoIhe respostas que o ajudem a sair de situações difíceis ${ }^{(18-22)}$.

E a última tendência a de impulso e determinação apresentouse presente em $73 \%$ dos formulários. Para esta dimensão observouse Que a grande maioria dos graduandos possui características Que para eles parecem ser relevantes como equilíbrio entre o resultado e o esforço dentro de determinadas atividades do saber, saber fazer e saber ser para fazer e conhecer.

\section{CONCLUSÕES E CONSIDERAÇÕES FINAIS}

O estudo com estudantes concluintes do curso de enfermagem demonstrou Que estes estudantes têm poucas tendências de empreendedorismo. Em meio a um mercado de trabalho cada vez mais competitivo, estes parâmetros indicam Que os estudantes podem possuir uma atitude interna desmotivadora de crescimento e enfrentamento deste panorama.

Ser empreendedor significa ter, acima de tudo, a necessidade de realizar coisas novas, pôr em prática idéias próprias, características de personalidade e comportamento, o Que nem sempre é fácil de encontrar.

Para Que o ensino do empreendedorismo se torne mais eficiente, é preciso adotar metodologias próprias, diferentes das adotadas para o ensino convencional. Nesses termos, é necessária uma abordagem andragógica e fundamentada no "aprender fazendo", Que utilize técnicas como oficinas, modelagem, estudos de caso, metáforas e dinâmicas. Por isso, também o professor precisa adeouar-se, tornando-se muito mais um incentivador e condutor de atividades do que alguém que dita procedimentos padrões. É necessário que também o professor seja empreendedor.

Diante dos resultados deste estudo, faz-se necessário Que seja repensado qual perfil é desejável para o enfermeiro. É necessário também que este perfil projetado seja orientado para as atividades sistêmicas e para os resultados, confiança em si mesmo, persistência e determinação, além de dedicação para concluir uma tarefa e alcançar as metas estabelecidas.

\section{REFERÊNCIAS}

1. Leite EF. Formação de Empreendedores e o papel das Incubadoras. Florianópolis: UFSC; 1999.

2. Leite EF. Empreendedorismo, inovação e incubação de empresas. Recife: Bagaço; 2006.

3. Souza C. Reinvente a sua carreira como um negógio. São Paulo: Intermanagers; ano. [citado em 17 set 2008]. Disponível em: http://www.internmanegers.com.br

4. Cunha CIC, Ferla L A. Iniciando seu próprio negócio. Florianópolis: Instituto de Estudos Avançados; 1997.

5. Shumpeter I. Theories of economic development. Cambridge: Harvard University Press; 1983.

6. Young R. Formação entrepreneurial e consolidação de desempenhoempresarial. Washington: Agência para o Desenvolvimento Internacional;; 1990.

7. Bernardi LA. Manual de empreendedorismo e gestão. São Paulo: Atlas; 2007.

8. Tenório FG, organizador. Responsabilidade social empresarial. Rio de Janeiro: FGV; 2006.

9. Chiavenato I. Introdução a teoria geral da administração. Rio de Janeiro: Elsevier; 2003.

10. Freire A. Paixão por empreender. Rio de Janeiro: Elsevier; 2005.

I1. Demac. Desarrollo de empreendedores. Cuidad de México: 
McGraw Hill; 1991.

12. Caird S. Testing enterprising tendency of occupational groups. British I Manag 1991; 2: 177-83.

13. Morin E. Os sete saberes necessários à educação do futuro. São Paulo: Cortez; 2001 .

14. Ruthes RM, Cunha ICKO. Gestão por competências nas instituições de saúde: uma aplicação prática. São Paulo: Martinari; 2008.

15. Martins C, Kobayashi RM, Ayoub AC, Leite MMI. Perfil do enfermeiro e necessidades de desenvolvimento de competência profissional. Texto Contexto Enferm 2006; 15(3): 472-8.

16. Zouain DM, Oliveira FB, Barone FM. Construindo o perfil do jovem empreendedor brasileiro. Rev Adm Pública 2007; 4 I (4): 797-807.

17. Faria MFB. Empreendedorismo: além do plano de negócio. Rev
Adm Contemp 2005; 9(4): 205.

18. Figueiredo MD. Empreendedorismo, inovação e incubação de empresas: lei de inovação. Rev Adm Contemp 2008; 12(1): 257-9.

19. Schmidt S, Bohnenberger MC. Perfil empreendedor e desempenho organizacional. Rev Adm Contemp 2009; I3(3): 450-67.

20. Backes DS, Backes MS, Erdmann AL. Promovendo a cidadania por meio do cuidado de enfermagem. Rev Bras Enferm 2009; 62(3): 430-4.

21. Lunardi Filho WD. A autonomia profissional do enfermeiro [editorial]. Enferm Brasil 2007; 6(3).

22. Cecagno D, Soares DC, Siqueira HCH, Cecagno S. Incubadora de aprendizagem: uma nova forma de ensino na Enfermagem/ Saúde. Rev Bras Enferm 2006; 59(6): 808-I I . 